\title{
A novel chemiluminescence assay of organophosphorous pesticide quinalphos residue in vegetable with luminol detection
}

\author{
Haoyu Hu, Xiaoyu Liu*, Feng Jiang, Xin Yao and Xiaocheng Cui
}

\begin{abstract}
Background: Organophosphorous pesticides are the most popular pesticides used in agriculture. As acetylcholinesterase inhibitors, organophosphorous pesticides are toxic organic chemicals. The control and detection of organophosphorous pesticide residue in food, water, and environment therefore plays a very important role in maintaining physical health. A sensitive, rapid, simple chemiluminescence $(\mathrm{CL})$ method has been developed for the determination of quinalphos based on the reaction of quinalphos with luminol- $\mathrm{H}_{2} \mathrm{O}_{2}$ in an alkaline medium. The method has been applied to detection of quinalphos in vegetable samples with satisfactory results.

Results: The $\mathrm{CL}$ method for the determination of organophosphorous pesticide quinalphos is based on the phenomenon that quinalphos can apparently enhance the $\mathrm{CL}$ intensity of the luminol- $\mathrm{H}_{2} \mathrm{O}_{2}$ system. The optimal conditions were: luminol concentration $5.0 \times 10^{-4} \mathrm{~mol} / \mathrm{L}, \mathrm{H}_{2} \mathrm{O}_{2}$ concentration $0.05 \mathrm{~mol} / \mathrm{L}$.pH value 13 . In order to restrain the interference from metal ions, $1.0 \times 10^{-3} \mathrm{~mol} / \mathrm{L}$ of EDTA was added to the luminol solution. The possible mechanism was proposed.

Conclusion: Under the optimum reaction conditions, $C L$ was linear with the concentration of quinalphos in the range of $0.02 \mu \mathrm{g} / \mathrm{mL}-1.0 \mu \mathrm{g} / \mathrm{mL}$ and the detection limit was $0.0055 \mu \mathrm{g} / \mathrm{mL}$ (3б). This method has been successfully applied to the detection of quinalphos in vegetable samples. According to the experimental data, the average recoveries for quinalphos in cherry tomato and green pepper $97.20 \%$ and $90.13 \%$. Meanwhile, the possible mechanism was proposed.
\end{abstract}

\section{Background}

Organophosphorus pesticides are widely used in agriculture due to their high insecticidal activity[1]. They are toxic organic chemicals which can irreversibly inhibit acetylcholinesterase $(\mathrm{AChE})$ which is essential for the function of the central nervous system [2,3]. As the pesticide residue is a potentially serious hazard to human health, the control and detection of pesticide residue plays a very important role in minimising risk[4]. Many methods have been developed in the last few years for the detection of organophosphorus pesticides. The most widely used methods are gas chromatography (GC) [5-7], high-performance liquid chromatography (HPLC) [8,9], gas chromatography-mass spectrometry(GC-MS) [10],

* Correspondence: liuxiaoyu1@hotmail.com

${ }^{1}$ College of Food Science and Techonolgy, Huazhong Agricultural University, Wuhan 430070, China

Full list of author information is available at the end of the article immune assay and fluorescence [11,12]. These methods are accurate and selective, but they require relatively expensive instrumentation and skilled technicians.

Chemiluminescence $(\mathrm{CL})$ is defined as the production of electromagnetic radiation (ultraviolet, visible or infrared) observed when a chemical reaction yields an electronically excited intermediate or end product, which either luminesces or donates its energy to another molecule responsible for the emission. The $\mathrm{CL}$ phenomenon can be applied as detection technique for the monitoring of a wide variety of compounds in diverse fields, such as clinical, pharmaceutical, biomedical, environmental and food analysis [13-15]. Compared with those methods mentioned above, the chemiluminescence(CL) method has been growing in popularity and acceptance because of its advantages such as high sensitivity, rapid assay speed and simple instrumentation. CL method has been<smiles>c1ccccc1</smiles> 
applied to the determination of organophosphorus pesticides residues during recent years[16-19].

Quinalphos (O,O-diethyl-O-quinoxalinyl phosphorothioate) is one of the most widely used organophosphorus insecticides in agriculture, and is applied to control of incidence of pests over crops such as cotton, tea, citrus and rice. At present, most of the analytical methods employed for the detection of quinalphos residues are based on chromatographic techniques [20], chromatographic techniques-mass spectrometry [21] and fluorescence. Until now, to our knowledge, there have been no reports of detecting quinalphos using a direct CL method. In our study, we found that the CL signal could be enhanced on the reaction of quinalphos with luminol$\mathrm{H}_{2} \mathrm{O}_{2}$ in alkaline medium. Based on these findings, a sensitive, simple CL method for the detection of quinalphos was developed. The method has been applied to the detection of quinalphos in vegetable samples with satisfactory results. Further study was focused on the mechanism of quinalphos and the possible mechanism was proposed.

\section{Results and Discussion Effect of luminol concentration}

As the CL reagent, luminol concentration was an important factor which affected the CL intensity. The effect of luminol concentration on the CL intensity was examined in the range of $1.0 \times 10^{-5} \mathrm{~mol} / \mathrm{L}-1.0 \times 10^{-3} \mathrm{~mol} / \mathrm{L}$, with 3 replicates. $\Delta \mathrm{I}$ (the increasing amount of $\mathrm{CL}$ intensity) reached the maximum value when the concentration of luminol solution was $5.0 \times 10^{-4} \mathrm{~mol} / \mathrm{L}$. Therefore, for the experiments, the concentration of luminol was maintained at the optimal value of $5.0 \times 10^{-4} \mathrm{~mol} / \mathrm{L}$.

\section{Effect of hydrogen peroxide concentration}

The effect of $\mathrm{H}_{2} \mathrm{O}_{2}$ concentration on the CL intensity was tested in the range of $0.05 \mathrm{~mol} / \mathrm{L}-1 \mathrm{~mol} / \mathrm{L}$, with 3 replicates. The result (Figure 1) showed that $\Delta \mathrm{I}$ reached the maximum value when the concentration of $\mathrm{H}_{2} \mathrm{O}_{2}$ was $0.05 \mathrm{~mol} / \mathrm{L}$. Therefore $0.05 \mathrm{~mol} / \mathrm{L}$ was chosen as the optimal $\mathrm{H}_{2} \mathrm{O}_{2}$ concentration for further experiment.

\section{Effect of $\mathrm{pH}$ of luminal}

The $\mathrm{pH}$ of the reaction of quinalphos with luminol- $\mathrm{H}_{2} \mathrm{O}_{2}$ in alkaline medium is an important parameter. The effects of a medium with $\mathrm{pH}$ in the range 12.5-13.5 were investigated, with 3 replicates. $\Delta \mathrm{I}$ reached the maximum value when the $\mathrm{pH}$ was 13 . Therefore $\mathrm{pH} 13$ of luminol solution was selected as optimum for consequent research [22].

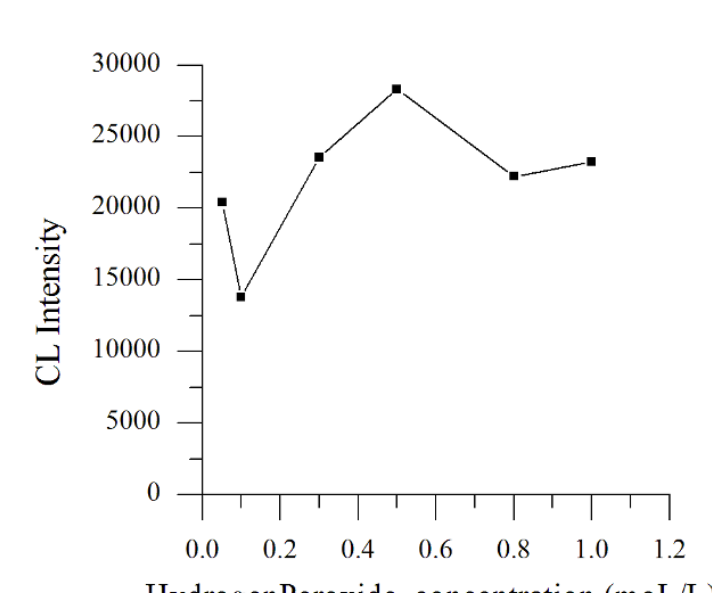

HydrogenPeroxide concentration $(\mathrm{moL} / \mathrm{L})$

Figure 1 Effect of $\mathrm{H}_{2} \mathrm{O}_{2}$ concentration on the $\mathrm{CL}$ intensity.

\section{Effect of enhancers}

Our preliminary experiment showed that the $\mathrm{CL}$ reaction of luminol- $\mathrm{H}_{2} \mathrm{O}_{2}$ - organophosphorus could be sensitized by several surfactants and inorganic salts. Surfactants can form micelles which can change the physical characteristics of molecular guests and their reactivity in aqueous solutions. Thus, two non-ionic surfactants (Tween-80, Polythylene Glucol-400(PEG-400)), two anionic surfactants (sodium dodecyl sulplhate (SDS), sodium dodecyl benzene sulplhate(SDBS)), one cationic surfactants (Cetyltrimethylammonium bromide (CTMAB)) and five inorganic salts $(\mathrm{KBr}, \mathrm{NaBr}, \mathrm{NaCl}, \mathrm{KI}, \mathrm{KCl})$ were tested. However, the results (Table 1) showed that the effect of enhancers were not obvious under strong alkaline condition and the CL intensity was even inhibited by some surfactants. It indicated that quinalphos can apparently enhance the $\mathrm{CL}$ intensity of the luminol- $\mathrm{H}_{2} \mathrm{O}_{2}$ system without sensitizers.

\section{Influence of coexisting foreign species}

The effect of some common inorganic ions and organic compounds on the CL reaction was tested by analyzing a standard solution of quinalphos $\left(1.0 \times 10^{-7} \mathrm{~g} / \mathrm{mL}\right)$ to which increasing amounts of foreign ions were added. The tolerance limit was taken as the amount which caused a relative error of $\pm 5 \%$ in the peak height. Because some metal ions such as $\mathrm{Cu}$ (II), Co (II) may interfere the CL system in the luminol-hydrogen peroxide method. The tolerable ratio for foreign species was 1000 -fold for glucose, $\mathrm{CO}_{3}{ }^{2-}, \mathrm{NO}_{3}{ }^{-}, \mathrm{Cl}^{-}, \mathrm{Na}^{+}$; 100 -fold for $\mathrm{Mg}^{2+}$; 1-fold for $\mathrm{Pb}^{2+} ; 0.01$-fold for $\mathrm{Co}^{2+}, \mathrm{Fe}^{3+}, \mathrm{Cu}^{2+}[23-26]$. It can be seen that obvious interference was caused by $\mathrm{Co}^{2+}, \mathrm{Fe}^{3+}$ and $\mathrm{Cu}^{2+}$. Thus, $1.0 \times 10^{-3} \mathrm{~mol} / \mathrm{L}$ of EDTA was added to 
Table 1: Selection of enhancers

\begin{tabular}{ccc}
\hline Enhancers & Concentration & The CL intensity of quinalphos \\
\hline CTMAB & $0.5 \%$ & 2012.8 \\
SDBS & $0.5 \%$ & 7671 \\
SDS & $0.5 \%$ & 3095 \\
Tween-80 & $0.5 \%$ & - \\
PEG-400 & $0.5 \%$ & - \\
$\mathrm{NaBr}$ & $1 \mathrm{~mol} \cdot \mathrm{L}-1$ & 9189 \\
$\mathrm{KBr}$ & $1 \mathrm{~mol} \cdot \mathrm{L}-1$ & 8658 \\
$\mathrm{KCl}$ & $1 \mathrm{~mol} \cdot \mathrm{L}-1$ & 7447 \\
$\mathrm{NaCl}$ & $1 \mathrm{~mol} \cdot \mathrm{L}-1$ & 10170 \\
$\mathrm{KI}$ & $1 \mathrm{~mol} \cdot \mathrm{L}-1$ & 8424 \\
\hline
\end{tabular}

the luminol solution to restrain the interference from metal ions.

\section{The analytical characteristic of the $\mathrm{CL}$ method}

Under the optimal conditions, the calibration curve of $\Delta \mathrm{I}$ against quinalphos concentration was linear in the range of $2 \times 10^{-8} \mathrm{~g} / \mathrm{mL}-1 \times 10^{-6} \mathrm{~g} / \mathrm{mL}$ and the calibration curves was $y=1081 \times-2650.4$ (where $\times$ is the concentration of quinalphos, $10^{-8} \mathrm{~g} / \mathrm{mL}$ ), with the correlation coefficient of 0.9921 . The detection limit of quinalphos was $0.0055 \mu \mathrm{g} /$ $\mathrm{mL}$, calculated from the International Union of Pure and

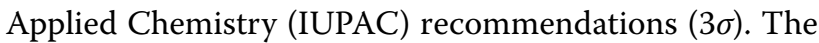
relative standard deviations (RSD) for 7 injections with 1 $\times 10^{-7} \mathrm{~g} / \mathrm{mL}$ quinalphos was $5.6 \%$.

\section{Sample analysis}

The proposed method was applied to the assay of quinalphos in vegetable sample. The eluent of quinalphos which was sprayed on the surface of vegetables was analyzed. According to the experimental data, the average recoveries for quinalphos in cherry tomato and green pepper $97.20 \%$ and $90.13 \%$ (Table 2). The relative standard deviations (RSD) for recoveries of quinalphos on the surface of cherry tomato and green pepper were $5.6 \%$ and $4.9 \%$.

\section{Kinetics curve of the $\mathrm{CL}$ reaction}

In this experiment, the kinetic characteristics of the proposed CL reaction were studied. The response curve of luminol $\left(5 \times 10^{-4} \mathrm{~mol} / \mathrm{L}\right) \mathrm{CL}$ reaction in the present quinalphos $\left(1 \times 10^{-7} \mathrm{~g} / \mathrm{mL}\right)$ was recorded to study the kinetic characteristic of the CL reaction. Figure 2 demonstrated that the CL intensity peak appeared within $1 \mathrm{~s}$ of the injection of the quinalphos. The CL signals would decrease to a very low level within $20 \mathrm{~s}$. The kinetic curve indicated the CL method was rapid and sensitive enough to be suitable for the detection of quinalphos.

\section{The $\mathrm{CL}$ reaction mechanism}

Many research works have focused on the CL reaction mechanism of the luminol system. The research results have confirmed that the 3 -aminophthalate anion was the emitter irrespective of medium and oxidant used. The maximum emission wavelength of luminol was about 420 $\mathrm{nm}$. The resulting fluorescence spectrum (Figure 3) indicated that the maximum emssion wavelength of three systems (Luminol, Lumino- $\mathrm{H}_{2} \mathrm{O}_{2}$ and quinalphosLumino- $\mathrm{H}_{2} \mathrm{O}_{2}$ ) was also near $420 \mathrm{~nm}$ and the signal of fluorescence emission spectrum of quinalphos-lumino$\mathrm{H}_{2} \mathrm{O}_{2}$ system is higher than lumino- $\mathrm{H}_{2} \mathrm{O}_{2}$ system. This means that the emitter of quinalphos-lumino- $\mathrm{H}_{2} \mathrm{O}_{2}$ system was also 3-aminophthalate anion.

Based on the analysis of the fluorescence spectrum combined with the kinetic curve, the possible mechanism of the present reaction was proposed as following: [1] Quinalphos was oxidized by $\mathrm{H}_{2} \mathrm{O}_{2}$ to peroxophosphonate;

Table 2: Analytical results of quinalphos in vegetable

\begin{tabular}{ccccc}
\hline Sample & Content of quinalphos & quinalphos Added & Found & Recovery (\%) \\
& & & \\
& None & $\left.1 \times 10^{-7} \mathrm{~g}\right)$ & $9.720 \times 10^{-8} \mathrm{~g}$ & 97.20 \\
Cherry tomato & None & $1 \times 10^{-7} \mathrm{~g}$ & $9.013 \times 10^{-8} \mathrm{~g}$ & 90.13 \\
\hline
\end{tabular}




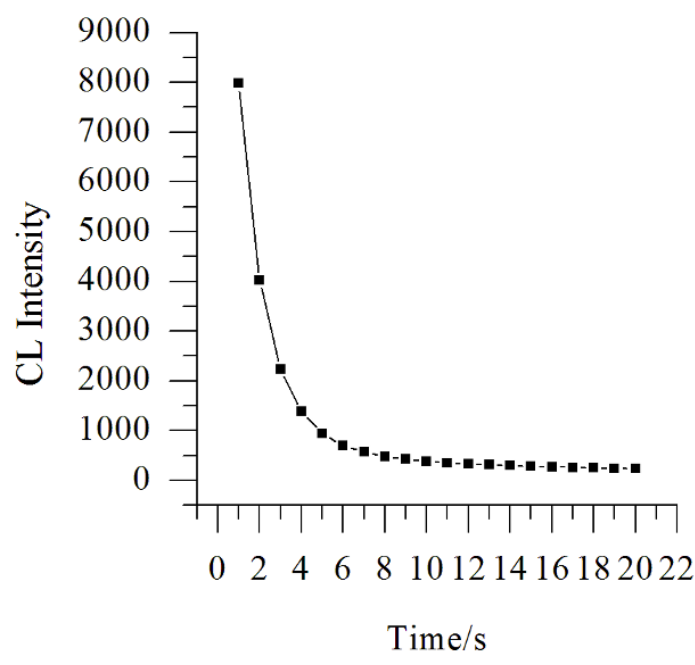

Figure 2 The kinetics curve of quinalphos -luminol $-\mathrm{H}_{2} \mathrm{O}_{2}$.

[2] Peroxophosphonate oxidized luminol to produce an excited state 3-aminophthalate anion; [3] The excited state 3-aminophthalate anion relaxed to the ground state, producing the observed emission $[27,28]$ (Figure 4).

\section{Conclusion}

In this work, a direct CL method for determination of quinalphos is presented based on the reaction with luminol- $\mathrm{H}_{2} \mathrm{O}_{2}$ in an alkaline medium. CL reaction could occur with lower concentration of quinalphos without enhanc-

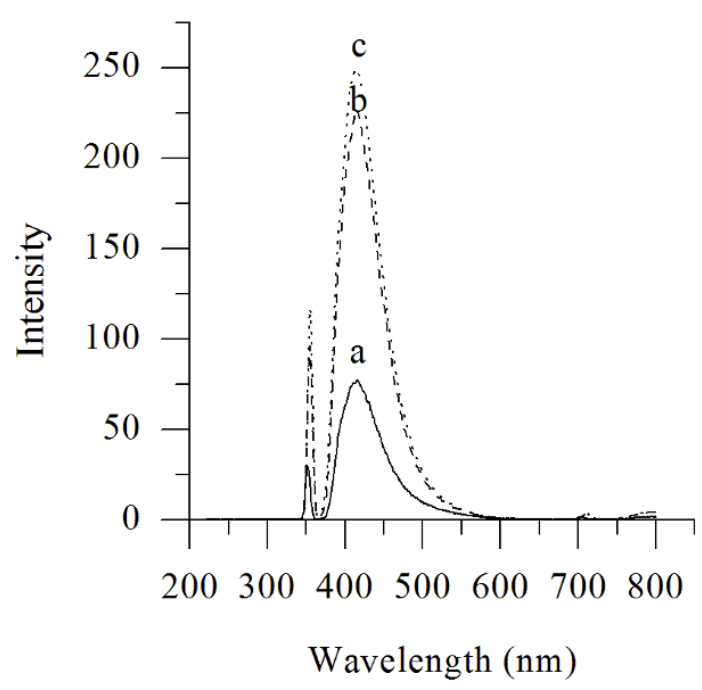

Figure 3 The fluorescence spectrum of the solutions. a. luminol solution b.luminol and $\mathrm{H}_{2} \mathrm{O}_{2}$ C. luminol- $\mathrm{H}_{2} \mathrm{O}_{2}$ - quinalphos ers such as organized surfactant. The method was applied to the detection of quinalphos in vegetable samples. In the following, the mechanism was also investigated in detail through examination of the fluorescence spectrum and kinetic curve.

\section{Experimental}

\section{Reagents and solutions}

All reagents were analytical reagent grade and distilled water was used throughout these experiments. Luminol (5-amino-2,3-dihydro-1, 4-phthalazinedione, 99\%) was purchased from the Corporation of Sigma(USA). Quinalphos standard solution $(0.1 \mathrm{mg} / \mathrm{mL}$ in acetone) was purchased from the Corporation of Standard Material (Beijing, China). Tween-80(Amresco), PEG-400(Guangdong, China), SDS(Guangdong, China), SDBS(Shanghai, China), CTMAB(Wuhan, China), KBr(Guangdong, China), $\mathrm{NaBr}$ (Tianjin, China), $\mathrm{NaCl}$ (Jiaozuo, China), $\mathrm{KI}($ Wuhan, China), $\mathrm{KCl}$ (Wuhan, China) were analytical reagent grade.

The $0.01 \mathrm{~mol} / \mathrm{L}$ luminol stock solution was prepared by dissolving $0.1772 \mathrm{~g}$ luminol with $2 \mathrm{~mL} 1 \mathrm{~mol} / \mathrm{L} \mathrm{NaOH}$ solution and diluted with distilled water to $100 \mathrm{ml}$. The luminol solution was stable for at least 1 week when stored in refrigerator at $4^{\circ} \mathrm{C}$. Working standard solutions of luminol were freshly prepared from the stock solution by appropriate dilutions before use and adjusted its $\mathrm{pH}$ with $0.1 \mathrm{~mol} / \mathrm{L} \mathrm{NaOH}$. The $0.01 \mathrm{mg} / \mathrm{mL}$ quinalphos stock solution was prepared by diluting $0.1 \mathrm{mg} / \mathrm{mL}$ standard solution of quinalphos with $1 \mathrm{~mL}$ acetone and then diluting to $10 \mathrm{~mL}$ with distilled water. The obtained stock solution was stored in refrigerator at $4^{\circ} \mathrm{C}$ [29-31].

\section{Apparatus}

The CL signal was measured by a BPCL ultra-weak luminescence analyzer (Institute of Biophysics, Chinese Academy of Science, Beijing, China) as shown in Figure 5. The CL intensity, amplified by a sensitive photomultiplier tube (PMT) operated at $-400 \mathrm{~V}$, was measured with a detector under the control of a computer. The CL intensity $\Delta \mathrm{I}$ was calculated by $\Delta \mathrm{I}=\mathrm{I}_{\mathrm{s}}-\mathrm{I}_{0}$, where $\mathrm{I}_{\mathrm{s}}$ and $\mathrm{I}_{0}$ are the CL signals in presence and absence of quinalphos respectively. The determination method was based on the relationship between $\Delta \mathrm{I}$ and corresponding concentration of quinalphos. The fluorescence spectrum was obtained by RF-5301PC fluorescence recording spectrophotometer (Shimadzu, Japan).

\section{Sample preparation}

The proposed method was utilized for the determination of quinalphos in vegetable sample. Cherry tomato and green pepper were bought from the market in our campus. The weight of cherry tomato was about $15 \mathrm{~g}$. The weight of green pepper was about $10 \mathrm{~g}$. They were 


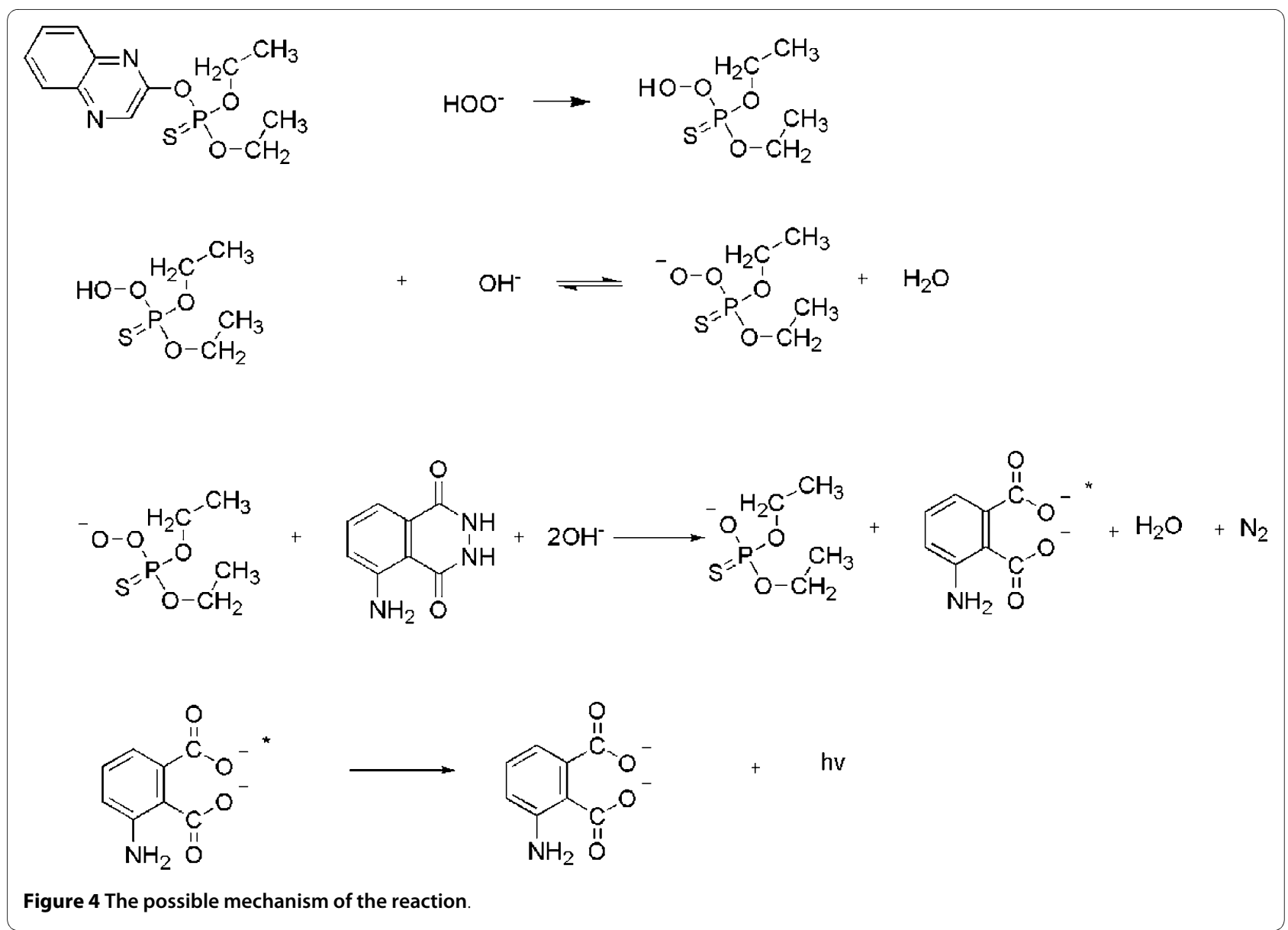

cleaned with distilled water. In order to perform the recovery test, a known amount of quinalphos standard solution was added to the sample and then washed with distilled water. The washings were diluted to suitable concentration with distilled water for analysis.

\section{U1tra-weak Luminescence Analyzer}

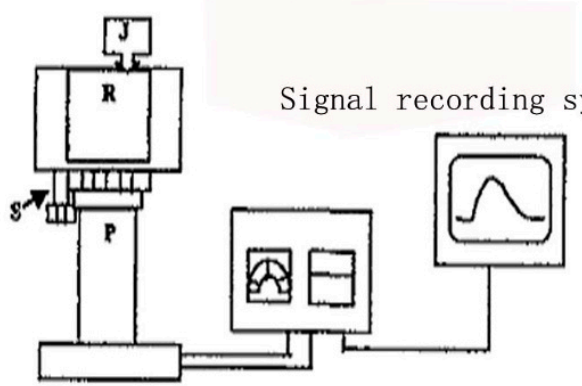

Figure 5 The detectable devices of static chemiluminescence. S: Switch P: Photomultiplier Tube J: Sample Injection R: Reaction Cell

\section{Competing interests}

The authors declare that they have no competing interests.

\section{Authors' contributions}

All authors contributed to the experimental design. Xiaoyu Liu focused on the experiment design and contributed to drafting the manuscript. Haoyu Hu and Feng Jiang carried out nearly all of the laboratory work. Xin Yao and Xiaocheng Cui deal with the data analysis. All authors read and approved the final manuscript.

\section{Acknowledgements}

This study was supported by the Tackle Key Project Foundation of Hubei Province of China (Grant No.2006AA201C40).

\section{Author Details}

College of Food Science and Techonolgy, Huazhong Agricultural University, Wuhan 430070, China

Received: 12 February 2010 Accepted: 24 June 2010 Published: 24 June 2010

\section{References}

1. Li AF, Liu XY, Kong J, Hu HY, Sun LH, Qian Z: Determination of organophosphorous pesticide phosphamidon in environmental water with luminol chemiluminescence detection. Journal of $A O A C$ International 2009, 92(3):914-918.

2. Taira K, Aoyama Y, Kawamata M: Long QT and ST-T change associated with organophosphate exposure by aerial spray. Environ Toxicol Pharmacol 2006, 22:40-45.

3. Shigeaki I, Takeshi S, Hiroyasu M, Yosuke S, Kensuke T, Isotoshi Y, Sadaki I: Rapid simultaneous determination for organophosphorus pesticides 
in human serum by LC-MS. Journal of Pharmaceutical and Biomedical Analysis 2007, 44:258-264.

4. $\mathrm{Li} B X, \mathrm{He}$ YZ, Xu CL: Simultaneous determination of three organophosphorus pesticides residues in vegetables using continuous-flow chemiluminescence with artificial neural network calibration. Talanta 2007, 72:223-230.

5. Ahmadi F, Assadi Y, Rezaee M: Determination of organophosphorus pesticides in water samples by single drop microextraction and gas chromatographyflame photometric detector. J. Chromatogra.A 2006, 1101(1-2):307-312.

6. Jin Y, Yao JB, Fu HB, Pan W, Geng QH, Ma W: Rapid determination of organophosphorus pesticide residues in vegetables and fruits by gas chromatography. Chinese Journal of Health Laboratory Technology 2007 17(7):1153-1154.

7. Li SX, Huang WX, Chen M: Detetmination of Chlorpyrifos in Water by Gas Chromatography. J Environ Health 2006, 23(5):458-459.

8. Benno A, Ruud C, Rob J, Hans G, Odile M: Determination of polar organophosphorus pesticides in aqueous samples by direct injection using liquid chromatography-tandem mass spectrometry. Journal of Chromatography A 2001, 918:67-78.

9. Martha P, María L: A validated matrix solid-phase dispersion method for the extraction of organophosphorus pesticides from bovine samples. Food Chemistry 2009, 114:1510-1516.

10. Lu JZ, Lau C, Lee MK, Ka M: Simple and convenient chemiluminescence method for the determination of melatonin. Analytical Letters 2002, 455:193-198.

11. Suvardhan K, Kumar K, Chiranjeevi P: Extractive Spectrofluorometric Determination of Quinalphos Using Fluorescein in Environmental Samples. Environmental Monitoring and Assessment 2005, 108:217-227.

12. Duran M, Muñoz de la Peña A, Acedo-Valenzuela Ml, Jiménez Girón A: Stopped-flow and kinetic-fluorimetric determination of quinalphos in water samples. Talanta 2006, 69(2):397-402.

13. José Antonio M, Aurelia Alañón M, Pablo Fernández L: Automatic chemiluminescence-based determination of carbaryl in various types of matrices. Talanta 2006, 68(3):586-593.

14. Lau C, Lu JZ, Kai M: Chemiluminescence determination of tetracycline based on radical production in a basic acetonitrile-hydrogen peroxide reaction. Anal Lett 2004, 503(2):235-239.

15. Li B, Zhang Z, Jin Y: Plant tissue-based chemiluminescence flow biosensor for glycolic acid. Anal Chem 2001, 73(6):1203-1206.

16. Gámiz-Gracia L, Garcia-Campaña AM, Soto-Chinchilla J, Huertas-Pérez JF, González-Casado A: Analysis of pesticides by chemiluminescence detection in the liquid phase. TrAC Trends in Analytical Chemistry 2005, 24:927-942.

17. Liu XY, Li AF, Chen M, Wu MC: Study on Chemiluminescence Assay of Organophoaphorous Pesticides Phoxim in Vegetable. Chinese Joumal of Analytical Chemistry 2007, 35:1809-1813.

18. Xie FR, Tu MZ, Xie ZH: Determination of Trichlorfon by Flow Injection Analysis with Chemiluminescence Detection. Chinese Journal of Spectroscopy Laboratory 2006, 23(3):644-647.

19. Li AF, Liu XY, Kong J, Huang R, Wu MC: Chemiluminescence Determination of Organophosphorus Pesticides Chlorpyrifos in Vegetable. Analytical Letters 2008, 41:1375-1386.

20. Jia GF, Lv CG, Zhu WT, Qiu J, Wang XQ, Zhou ZQ: Applicability of cloud point extraction coupled with microwave-assisted back-extraction to the determination of organophosphorous pesticides in human urine by gas chromatography with flame photometry detection. Journal of Hazardous Materials 2008, 159:300-305.

21. Gallardo E, Barroso M, Margalho C, Cruz A, Vieira DN, López-Rivadulla M: Determination of quinalphos in blood and urine by direct solid-phase microextraction combined with gas chromatography-mass spectrometry. Journal of Chromatography B 2006, 832(1):162-168.

22. Wang JN, Zhang C, Wang HX, Yang FZ, Zhang XR: Development of a luminol-based chemiluminescence flow-injection method for the determination of dichlorvos pesticide. Talanta 2001, 54(6):1185-1193.

23. Hu YG, Yang ZY: Flow Injection-chemiluminescence Method for the Determination of Trace Cu2+ in Environmental Samples. Journal of Analytical Science 2004, 20(2):148-150.

24. Denis B, Paolo P, Gabriella F, Carlo M: Effect of eluent composition and $\mathrm{pH}$ and chemiluminescent reagent $\mathrm{pH}$ on ion chromatographic selectivity and luminol-based chemiluminescence detection of $\mathrm{Co} 2+$ $\mathrm{Mn2}+$ and Fe2+ at trace levels. Talanta 2007, 72(1):249-255.
25. Li BX, Wang DM, Lv JG, Zhang ZJ: Flow-injection chemiluminescence simultaneous determination of cobalt(II) and copper(II) using partial least squares calibration. Talanta 2006, 69(1):160-165

26. Guo XM, Xu XD, Zhang J: A novel method for $\mathrm{Co}(\mathrm{II})$ and $\mathrm{Cu}(\mathrm{II})$ analysis by capillary electrophoresis with chemiluminescence detection. Chin Chemical Letters 2007, 18(9):1095-1098.

27. White EH, Bursey MM: Chemiluminescence of luminol and related hydrazedes: the light step. J Am Chem Soc 1964, 86:940-942.

28. Zhang Z, Lu J, Zhang X: Luminol chemiluminescence reation in analytical chemistry. Chin Chemical Reagents 1987, 9(3):149-156.

29. Jiang CQ, Luo L: Spectrofluorimetric determination of human serum albumin using a doxycycline-europium probe. Analytica Chimica Acta 2004, 506(2):171-175.

30. Liu X, Du J, Lu J: Determination of parathion residues in rice samples using a flow injection chemiluminescence method. Luminescence 2003, 18:245-248

31. Rao Z, Wang J, Zhang X: Determination of methyl-parathion using luminol-based chemiluminescence flow injection method. Chin J Anal Chem 2001, 29(4):373-377.

doi: 10.1186/1752-153X-4-13

Cite this article as: Hu et al., A novel chemiluminescence assay of organophosphorous pesticide quinalphos residue in vegetable with luminol detection Chemistry Central Journal 2010, 4:13

\section{Publish with ChemistryCentral and every scientist can read your work free of charge \\ "Open access provides opportunities to our colleagues in other parts of the globe, by allowing anyone to view the content free of charge." \\ W. Jeffery Hurst, The Hershey Company.}

- available free of charge to the entire scientific community

- peer reviewed and published immediately upon acceptance

- cited in PubMed and archived on PubMed Central

- yours - you keep the copyright

Submit your manuscript here

http://www.chemistrycentral.com/manuscript/

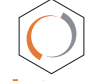

Chemistry Central 